\title{
Baseline Levels of Rapid Eye Movement Sleep May Protect Against Excessive Activity in Fear-Related Neural Circuitry
}

\author{
Itamar Lerner, ${ }^{\star}$ Shira M. Lupkin, ${ }^{\star}$ Neha Sinha, Alan Tsai, and Mark A. Gluck \\ Center for Molecular and Behavioral Neuroscience, Rutgers University, Newark, New Jersey 07102
}

\begin{abstract}
Sleep, and particularly rapid eye movement sleep (REM), has been implicated in the modulation of neural activity following fear conditioning and extinction in both human and animal studies. It has long been presumed that such effects play a role in the formation and persistence of posttraumatic stress disorder, of which sleep impairments are a core feature. However, to date, few studies have thoroughly examined the potential effects of sleep prior to conditioning on subsequent acquisition of fear learning in humans. Furthermore, these studies have been restricted to analyzing the effects of a single night of sleep-thus assuming a state-like relationship between the two. In the current study, we used long-term mobile sleep monitoring and functional neuroimaging (fMRI) to explore whether trait-like variations in sleep patterns, measured in advance in both male and female participants, predict subsequent patterns of neural activity during fear learning. Our results indicate that higher baseline levels of REM sleep predict reduced fear-related activity in, and connectivity between, the hippocampus, amygdala and ventromedial PFC during conditioning. Additionally, skin conductance responses (SCRs) were weakly correlated to the activity in the amygdala. Conversely, there was no direct correlation between REM sleep and SCRs, indicating that REM may only modulate fear acquisition indirectly. In a follow-up experiment, we show that these results are replicable, though to a lesser extent, when measuring sleep over a single night just before conditioning. As such, baseline sleep parameters may be able to serve as biomarkers for resilience, or lack thereof, to trauma.
\end{abstract}

Key words: fear learning; fMRI; PTSD; rapid eye movement sleep; REM sleep; sleep

\section{Significance Statement}

Numerous studies over the past two decades have established a clear role of sleep in fear-learning processes. However, previous work has focused on the effects of sleep following fear acquisition, thus neglecting the potential effects of baseline sleep levels on the acquisition itself. The current study provides the first evidence in humans of such an effect. Specifically, the results of this study suggest that baseline rapid eye movement (REM) sleep may serve a protective function against enhanced fear encoding through the modulation of connectivity between the hippocampus, amygdala, and the ventromedial PFC. Building on this finding, baseline REM measurements may serve as a noninvasive biomarker for resilience to trauma or, conversely, to the potential development of posttraumatic stress disorder following trauma.

\section{Introduction}

Posttraumatic stress disorder (PTSD) is a clinical disorder caused by experiencing or witnessing a traumatic event. However, only a subset of people who experience a trauma go on to develop PTSD.

\footnotetext{
Received March 1, 2017; revised Sept. 17, 2017; accepted Sept. 20, 2017

Author contributions: I.L., S.M.L., and M.A.G. designed research;S.M.L. and A.T. performed research; I.L., S.M.L., and N.S. analyzed data; I.L. and S.M.L. wrote the paper.

This work was supported by the National Science Foundation (NSF/BCS 1461009). We thank Ed Pace-Schott for his invaluable advice throughout the course of this study.

*I.L. and S.M.L. contributed equally to this work.

The authors declare no competing financial interests.

Correspondence should be addressed to Itamar Lerner or Shira Lupkin, Center for Molecular Neuroscience,

Rutgers University, 197 University Avenue, Newark, NJ 07102. E-mail: itamar.lerner@gmail.com or shiralupkin@gmail.com.

DOI:10.1523/JNEUROSCI.0578-17.2017

Copyright $($ C) 2017 the authors $\quad 0270-6474 / 17 / 3711233-12 \$ 15.00 / 0$
}

As such, the identification of potential biological risk factors has become a topic of particular interest in the scientific community. Accumulating evidence from human and animal studies has suggested that sleep may contribute to both the development and maintenance of the disorder (Germain et al., 2008). To date, however, the exact mechanisms remain elusive.

A common model for studying PTSD is fear conditioning, in which a neutral stimulus serving as the conditioned stimulus (CS; e.g., a light) is repeatedly paired with an aversive stimulus (unconditioned stimulus (US); e.g., an electric shock) until subjects learn to associate the CS with the US. This association is then often extinguished by repeatedly presenting the CS without the US. Previous studies have pointed to a bidirectional relationship between sleep, and particularly rapid eye movement (REM) sleep, and various aspects of the conditioning process whereby 
conditioning itself affects subsequent REM, which, in turn, increases both extinction recall and the generalization of extinction to similar stimuli (Fu et al., 2007; Pawlyk et al., 2008; Pace-Schott et al., 2009, 2015; Spoormaker et al., 2012).

In addition to behavioral findings, rodent in vivo recordings and functional neuroimaging in humans have pointed to three key brain regions associated with the conditioning process: the amygdala, the ventromedial prefrontal cortex (vmPFC), and the hippocampus (Pace-Schott et al., 2015). Previous studies have implicated both sleep in general and REM in particular in the modulation of activity in and between these three regions. This modulation is theorized to result in the reduction of emotional tone attached to a memory (for review, see Pace-Schott et al., 2015; Walker and van Der Helm, 2009).

While the aforementioned studies concentrated on the way sleep affects — and is affected by - the processing and consolidation of fear learning, a much neglected question is whether regular sleep patterns prior to initial fear exposure also play a role. The ability of sleep to influence subsequent emotional learning is well recognized (Yoo et al., 2007), but few studies have examined this question in regard to associative fear learning in humans, and those that have did not find substantial effects (Marshall et al., 2014; Peters et al., 2014). However, emerging evidence from rodent studies indicates that the number of REM episodes in the $24 \mathrm{~h}$ before fear conditioning predicts the subsequent degree of startle response to a CS (Polta et al., 2013). The lack of data concerning the effects of sleep on conditioning in humans is especially surprising given that several studies have shown self-reported measures of sleep before a trauma to be predictive of future PTSD symptomatology (Mellman et al., 1995; Wright et al., 2011; Gehrman et al., 2013).

Additionally, existing studies have primarily restricted their analyses to a single night of sleep. Thus, findings linking sleep to fear learning have been treated as state-dependent effects, reflecting the way the sleeping brain processes newly formed fear associations. An alternative account, however, is that these effects are the result of a trait-like relationship between sleep and fear learning. Indeed, in a previous study (Lerner et al., 2016), we found that across subjects, baseline REM sleep levels measured over multiple days were better predictors of individuals' emotional reactivity than the daily variations in REM.

In light of these previous findings, the current study sought to investigate whether baseline sleep parameters, especially REM, obtained before the experimental procedures, are predictive of fear learning measures. Given the direct relevance of fear learning to the development of PTSD, such results would suggest that pretrauma sleep patterns could serve as biomarkers for resilience (or a lack thereof) to trauma.

\section{Materials and Methods \\ Experiment 1 \\ Methods}

Participants. Seventeen healthy students ( $n=5$ females) from Rutgers University and the New Jersey Institute of Technology participated in this study for monetary compensation. Exclusion criteria included personal or family history of sleep problems, neurological or psychiatric disorders, drug or alcohol abuse, and/or intake of medications that have any effect on sleep. Three additional participants that passed the criteria were nevertheless dismissed from the study: one for failing to appear for a scanning session, one due to a lack of reliable use of equipment resulting in three or more experimental days of unusable sleep data, and one whose structural scan revealed severe hydrocephalus. Through-
Table 1. Participant demographics and sleep parameters (Experiment 1)

\begin{tabular}{lr}
\hline Demographics/sleep & Mean (SD) \\
\hline Age (years) & $22.6(2.1)$ \\
Education (years) & $16.0(1.5)$ \\
TST (minutes) & $416.02(36.72)$ \\
N1/N2 (minutes) & $200.34(35.75)$ \\
\%N1/N2 out of TST & $0.45(0.070)$ \\
SWS (minutes) & $81.50(20.93)$ \\
\%SWS out of TST & $0.20(0.055)$ \\
REM (minutes) & $134.2(21.56)$ \\
\%REM out of TST & $0.32(0.050)$ \\
\hline
\end{tabular}

out the experiment, participants were asked to not increase their daily caffeine intake, to maintain their regular sleep schedule, and to refrain from alcohol consumption and daytime napping (see demographic information and average sleep measures in Table 1). All participants provided informed consent in line with the procedures approved by the Institutional Review Board of Rutgers University.

Experimental design. The study consisted of two phases: a baseline sleep-monitoring phase and an experimental phase. During the sleep-monitoring phase, participants monitored their sleep at home for approximately 1 week (mean, $7.88 \mathrm{~d}$; range, 5-13 d). Before beginning this phase, participants were given detailed instructions and demonstrations on the care and use of all sleep-monitoring devices. In addition, they were instructed to keep a sleep log noting their sleep/wake times and any known nocturnal awakenings. Last, they were instructed to send both the data from the monitoring devices and a picture of their log to a secure email address, monitored daily by experimenters. Together, these data were used to assure that participants adapted to the usage and operation of the devices as well as to assess participants' reliability in following the sleep-monitoring protocols (i.e., consistently emailing data, ensuring that no data were missing because of the sleep-monitoring devices malfunctioning, etc.).

The experimental phase, which followed immediately after, included two functional brain-imaging scans, separated by $24 \mathrm{~h}$ (for illustration, see Fig. 1). During this phase participants underwent a fear conditioning procedure with concurrent skin conductance response (SCR) recording and functional imaging. Detailed procedures for these scanning sessions are presented below.

Mobile sleep-monitoring system. The mobile sleep-monitoring system included an automated wireless sleep-monitoring headband (Zeo), an actigraphy bracelet (Micro MotionLogger sleep watch, Ambulatory Monitoring), and an Android tablet (Amazon).

The sleep-monitoring headband is equipped with a single bipolar fabric sensor that transmits data wirelessly to the Android tablet, which acts as a base station. The sensor is fitted with three silver-coated electrodes used to detect brain waves (EEG), eye movements (EOG), and the movement of the frontalis muscle (EMG). The signals from these electrodes are analyzed in real time to produce sleep staging in $30 \mathrm{~s}$ epochs. This sleep staging, the accuracy of which was validated for nocturnal sleep compared to polysomnography (PSG) in multiple studies (Shambroom et al., 2012; Griessenberger et al., 2013) is a reduced version of the official staging criteria by the American Association of Sleep Medicine (Iber et al., 2007) and differentiates between four stages of sleep: wake, N1/N2 (combined N1 and N2 stages, termed "light sleep"), slow-wave sleep (SWS) (“deep sleep"), and REM sleep.

The actigraphy bracelet is a research-grade device that contains a built-in accelerometer used to infer sleep/wake decisions 


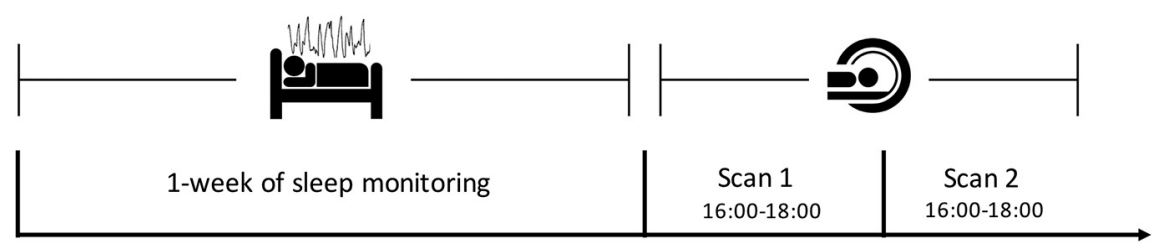

Figure 1. Illustration of study design.

\section{Scan 1: Evening}
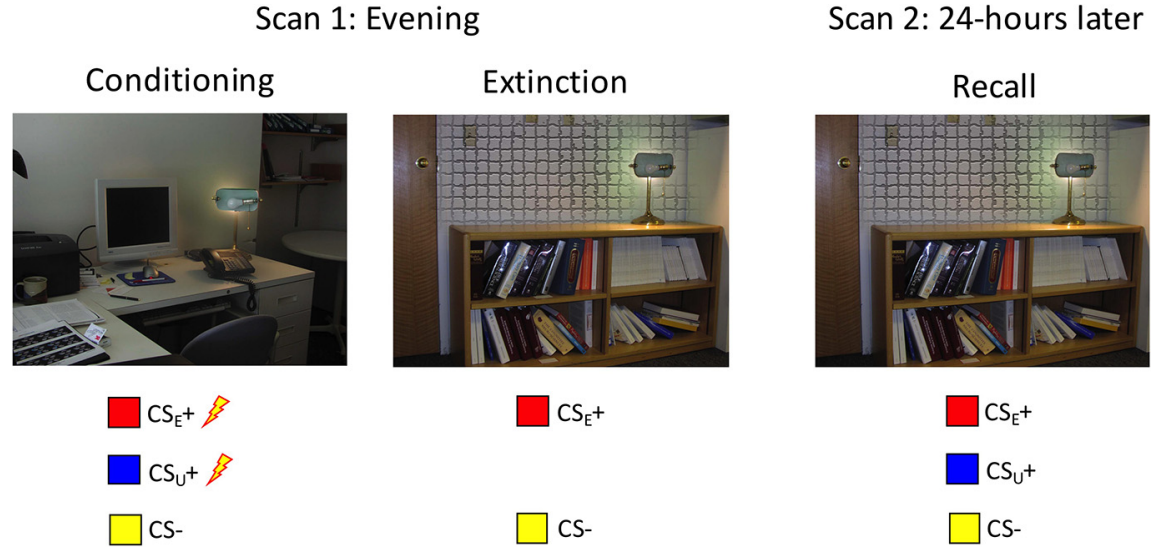

Figure 2. Schematic of the experimental paradigm. $\mathrm{CS}_{\mathrm{E}}+$ is the conditioned stimulus that was to be extinguished, $\mathrm{CS}_{U}+$ is the conditioned stimulus that was never extinguished, and $\mathrm{CS}-$ is the stimulus that was never conditioned, which served as a control. Pairing with the US is denoted by lightening bolts.

in 1 min epochs based on participants' arm movements using the Cole-Kripke algorithm (Cole et al., 1992; Ancoli-Israel et al., 2003; de Souza et al., 2003). Participants wore the actigraph on the nondominant wrist throughout the entire study. Data were extracted from the devices at the end of the experiment and used to assess the sleep/wake validity of the sleep-monitoring headband (for details, see Lerner et al., 2016). Only data that were consistent across the headband, the actigraph, and the subjects' sleep logs were used for further analysis ( $94 \%$ of the total data). Finally, data for each participant were averaged over all valid nights to create a trait-level sleep profile of that participant, including average time in each sleep stage as well as percentage of time in a sleep stage out of total sleep time (TST).

Fear learning paradigm and stimuli. The fear learning paradigm was split into three phases across the two scanning sessions (following Milad et al., 2007a,b). The first day included both conditioning and extinction phases, and the second day consisted of a recall phase. The CS across the two days was comprised of images of three differently colored lamps (blue, yellow, and red) presented in two different contexts (Fig. 2). For each subject, two of the CSs were paired with the US. One, denoted as $\mathrm{CS}_{\mathrm{E}}+$, was later extinguished; the other, denoted as $\mathrm{CS}_{U}+$, remained unextinguished for the rest of the experiment. The third CS, referred to as CS-, was not paired with the US. All phases contained 32 stimulus presentation trials. Each trial began with the presentation of the context, alone, for three seconds, followed by a CS for an additional six seconds. Following CS offset, mild electrical stimulation (serving as the US) was administered for $500 \mathrm{~ms}$ for select trials (see Experimental procedure for details). By avoiding temporal overlap between the CS + and the US, potential confounding of the anticipatory response to the US and the physiological responses to the electric stimulation was minimized (cf. Fullana et al., 2016; Table 1, Study 16 of Milad 2007b, which used the same methodology as ours). The intertrial interval was a black screen that lasted 12,15 , or $18 \mathrm{~s}$.
In the conditioning phase, all three CS types were presented in context $\mathrm{A}$. Both the $\mathrm{CS}_{\mathrm{E}}+$ and the $\mathrm{CS}_{\mathrm{U}}+$ (eight trials in total for each) were paired with the US at a partial reinforcement rate of $60 \%$. The CS(16 trials) was never paired with the US. Next, participants underwent the extinction phase in which the $\mathrm{CS}_{\mathrm{E}}+$ was presented in context $\mathrm{B}$ along with the CS- (16 presentations of each). During extinction, neither stimulus was paired with the US, thus extinguishing the response to the $\mathrm{CS}_{\mathrm{E}}+$. The $\mathrm{CS}_{\mathrm{U}}+$ was not presented during the extinction phase and was therefore left unextinguished. During the recall phase, all three $\mathrm{CSs}\left(\mathrm{CS}_{\mathrm{E}}+\right.$, $\mathrm{CS}_{\mathrm{U}}+, \mathrm{CS}-$ ) were presented in context $\mathrm{B}$ without the US.

The presentation of the $\mathrm{CS}_{\mathrm{E}}+$ and the $\mathrm{CS}_{\mathrm{U}}+$ in the conditioning and recall phases was blocked such that during the first half of the session, only one of them was presented interspersed with the CS(eight trials of each), whereas during the second half, the other was interspersed with the CS- (eight trials of each). This type of blocking was shown by Milad et al. (2007a) to improve the conditioning response to each of the respective CS+'s. The identities of each of the CSs were counterbalanced across colors and participants, as was the order in which the blocks were presented (i.e., whether the block containing the $\mathrm{CS}_{\mathrm{U}}+$ or the $\mathrm{CS}_{\mathrm{E}}+$ came first in conditioning and recall).

The data from each of the conditioning, extinction, and recall phases were organized into four contrasts that were used in subsequent analysis: conditioning, extinction, fear recall/extinction retention, and generalization. Contrasts were defined following Milad et al. (2007a): for conditioning, the first four trials of each $\mathrm{CS}+$ versus the $\mathrm{CS}-$ during the conditioning phase $\left(\mathrm{CS}_{\mathrm{E}}+\right.$, $\mathrm{CS}_{\mathrm{U}}+>\mathrm{CS}-$ ); for extinction, the last $12 \mathrm{CS}_{\mathrm{E}}+$ trials versus the $\mathrm{CS}-$ during the extinction phase $\left(\mathrm{CS}_{\mathrm{E}}+>\mathrm{CS}-\right)$; for fear recall/extinction retention, the first four $\mathrm{CS}_{\mathrm{E}}+$ trials versus the $\mathrm{CS}-$ during the recall phase $\left(\mathrm{CS}_{\mathrm{E}}+>\mathrm{CS}-\right)$; and for generalization of fear of the unextinguished stimulus, the first four $\mathrm{CS}_{\mathrm{U}}+$ versus the $\mathrm{CS}-$, also during the recall phase $\left(\mathrm{CS}_{\mathrm{U}}+>\mathrm{CS}-\right)$.

Experimental procedure. After monitoring their sleep for at least 5 consecutive days, subjects arrived to the scanning facility between 4:00 P.M. and 5:00 P.M. Subjects were placed in the scanner where SCR and stimulation electrodes were attached to their hands (for details, see below, Skin conductance analyses). Next, subjects underwent an incremental titration procedure to select their individual electric stimulation threshold (Milad et al., 2007a). Increasing intensities of a 0.5 s mild electric shock (from 0.2 to $4.0 \mathrm{~mA}$ across up to 8 increments) were administered to the index and middle fingers of each subject's dominant hand using a Coulbourn Transcutaneous Aversive Finger Stimulator until the subject chose a level that was deemed "highly annoying but not painful." Shock increments were then stopped, and subjects were informed that the level they had selected would be used throughout the subsequent experiment. Before beginning the conditioning protocol, subjects went through a habituation phase during which they were presented with all three CSs (i.e., colored lights) in both the conditioning and the extinction contexts, in the ab- 
sence of any US. Each stimulus-context pairing was presented four times, counterbalanced across both the stimuli and the contexts. Following habituation, subjects were administered the conditioning and extinction procedures (as described above), after which they went home for the night. Subjects returned the following day between 4:00 P.M. and 5:00 P.M. to undergo the recall protocol.

\section{Statistical analyses}

Skin conductance analyses

SCR was recorded using two $11 \mathrm{~mm}$ (sensor diameter) $\mathrm{Ag} / \mathrm{AgCl}$ electrodes, with isotonic electrolyte gel (Biopac Systems). The electrodes were attached to the anterior surface of the medial phalanx on the subject's index and middle fingers of their nondominant hand. Skin conductance was recorded using the GSR100c amplifier on the MP150 data acquisition unit (Biopac Systems). Square pulse event markers were transmitted from the stimulus presentation software (Superlab 5.0, Cedrus), on a PC, via a PCI-DIO24 digital input/output card to the MP150 and AcqKnowledge version 4.4.2 software using a BIOPAC STP100C optical interface (Biopac Systems). Skin conductance levels were measured in microsiemens and collected at a sampling rate of $2 \mathrm{kHz}$. Due to equipment failure, Session 1 (conditioning and extinction phases) of one subject and Session 2 (recall phase) of another subject were unavailable for analysis and treated as missing data. In the second case, imaging data were also unavailable for that session.

Following Milad et al. (2007a), for each trial, of each phase, the SCR was calculated by taking the square root of the mean SCR value in the two seconds before stimulus onset, subtracted from the peak SCR value in the six seconds following stimulus onset. If the difference between the mean SCR and the peak SCR was less than zero, the square root of the absolute value was taken and then multiplied by negative one, to preserve the direction of the relationship after the initial subtraction. Contrasts were then computed by subtracting the mean of one type of stimulus (i.e., CS - ) from another (i.e., $\mathrm{CS}_{\mathrm{E}}+$ ), to be entered as covariates in the imaging analyses (see below, Imaging parameters and preprocessing).

\section{Imaging parameters and preprocessing}

Functional imaging was conducted at the National Science Foundation-funded Rutgers University Brain Imaging Center. Images were obtained using a Siemens Trio 3T full-body scanner with a 32 channel head coil. First, anatomical images were acquired using a T1-weighted protocol (MPRAGE, $1761 \mathrm{~mm}$ isotropic sagittal slices). These images were used for spatial normalization during analyses. Next, functional images (i.e., BOLD) were acquired using a single-shot gradient echo EPI sequence (TR, $2000 \mathrm{~ms}$; TE, 23 ms; FOV, $192 \mathrm{~cm}$; flip angle, $90^{\circ}$; bandwidth, $4340 \mathrm{~Hz} / \mathrm{px}$; echo spacing, $0.51 \mathrm{~ms})$. In total, 37 contiguous oblique-axial slices $(3 \mathrm{~mm}$ isotropic voxels) were obtained for all BOLD sequences.

Analysis of imaging data was conducted using FSL (FMRIB Software Library; Dégenètais et al., 2003). Skull stripping was conducted using the FSL brain extraction (BET; Smith, 2002) with the center of gravity of each image as a reference point. For each participant, BOLD images were registered to their structural images and then to a standard MNI-152 $2 \mathrm{~mm}$ template (degrees of freedom, 9; cost function, normalized mutual information; interpolation, sinc function) using FSL's linear registration tool (Jenkinson and Smith, 2001; Jenkinson et al., 2002).

Individual- and group-level whole-brain general linear model (GLM) analyses were conducted using the fMRI Expert Analysis Tool utility with motion correction, $5 \mathrm{~mm}$ FWHM spatial smooth-
Table 2. Participant demographics and sleep parameters (Experiment 2)

\begin{tabular}{lc}
\hline Demographics/sleep & Mean (SD) \\
\hline Age (years) & $21.82(3.29)$ \\
Education (years) & $15.10(2.02)$ \\
TST (minutes) & $325.41(145.88)$ \\
N1 (minutes) & $8.06(5.14)$ \\
\%N1 out of TST & $0.033(0.027)$ \\
N2 (minutes) & $194.74(93.91)$ \\
\%N2 out of TST & $0.59(0.11)$ \\
SWS (minutes) & $59.59(27.60)$ \\
\%SWS out of TST & $0.21(0.11)$ \\
REM (minutes) & $63.03(55.98)$ \\
\%REM out of TST & $0.17(0.10)$
\end{tabular}

ing, and high-pass temporal filtering. A trial averaging window of $12 \mathrm{~s}(6 \mathrm{TR})$ was used beginning from trial onset. At the group level, one GLM analysis was performed for each of the four contrasts (conditioning, extinction, recall, and generalization, as defined above). For each GLM analysis, demeaned values of skin conductance contrasts (as defined earlier) and sleep parameters (raw averages, over the baseline monitoring period, of the total time in each of the three sleep stages per night) were entered as four simultaneous covariates of interest. The FLAME 1 (FMRIB's Local Analysis of Mixed Effects) mixed-effects model was used, resulting in 12 degrees of freedom for each GLM analysis. Group level $Z$ statistic maps were generated for each of the main effects of the contrasts, as well as for the effects of each of the covariates, with the FSL cluster correction at $Z=2.3$ and a familywise error threshold of $p<0.05$. Additional group-level analyses were run using total sleep time. Finally, if any of the sleep parameters proved significant, another GLM analysis was run, using, as a single sleep covariate, the percentage of the time in that sleep stage out of total sleep time.

Evidence of significant activity for the main effects as well as the effects of the covariates was examined in three a priori regions of interest (ROIs; amygdala, hippocampus, vmPFC) chosen based on their established roles in fear learning. $Z$ statistics are reported for the peak voxel for each effect along with the corresponding Bonferroni-corrected $p$ values.

\section{Effective connectivity analysis}

To estimate potential causal relationships among relevant brain areas, an effective connectivity analysis was conducted using graphical causal modeling with independent multiple sample greedy equivalence search (IMaGES) and linear non-Gaussian orientation, fixed structure (LOFS) algorithms (Ramsey et al., 2010, 2011, 2014; Mumford and Ramsey, 2014), implemented using Tetrad IV (version 5.0.0-1; http://www.phil.cmu.edu/projects/tetrad) software.

The timing files for the CS presentation were weighted by CS - identity ( 1 for CS + and -1 for CS - ) and convolved with a double gamma hemodynamic response function. This convolved time series was then multiplied, elementwise, by the mean time series for each ROI. These new time series were entered into the IMaGES algorithm with each ROI representing a node in the network. The IMaGES algorithm searches for all potential connections and produces directed acyclic graphs (DAGs) containing all statistically significant connections. These DAGs are then fed to the LOFS algorithm to determine the orientation of each connection. For each subject, parameter values are assigned to each connection indicating the strength of that connection (termed "edge coefficients"). Correlations between these values, SCRs, and sleep parameters were carried out using Matlab 2016a (MathWorks). 

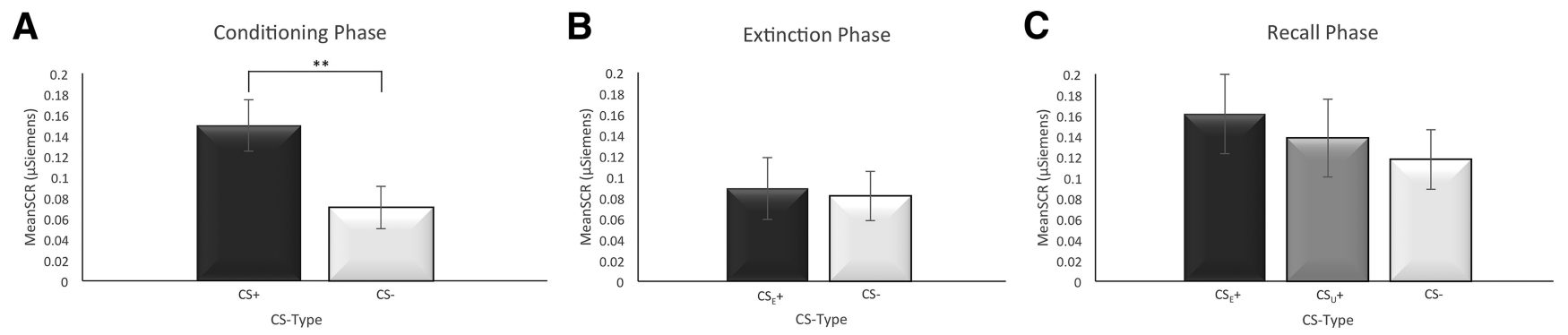

Figure 3. $\boldsymbol{A}-\boldsymbol{C}$, Comparison of SCR between $\mathrm{CS}$ types for the conditioning $(\boldsymbol{A})$, extinction $(\boldsymbol{B})$, and recall $(\boldsymbol{C})$ phases. ${ }^{* *} p<0.01$. Error bars indicate SEM.

\section{Image presentation}

The statistical maps generated as part of the ROI GLM analyses were thresholded and overlaid onto a three-dimensional rendering of the MNI-152 using Surf Ice (McCausland Center for Brain Imaging, Columbia, SC; see Figs. 4, 8). Scatter plots for the ROI analyses were created for illustration purposes by plotting the mean parameter estimates across the thresholded and overlapping voxels of a given effect as a function of percentage REM or SCR contrast values for each subject.

\section{Experiment 2}

Methods

Participants. Seventeen healthy students ( $n=5$ females) from Rutgers University and the New Jersey Institute of Technology participated in this study for monetary compensation (see demographic information and average sleep measures in Table 2). Exclusion criteria were the same as in the first study. All participants provided informed consent in line with the procedures approved by the Institutional Review Board of Rutgers University.

Study design. Participants came to the lab at approximately 8:00 P.M. the evening before the scan. During this visit, experimenters applied the PSG montage and instructed participants on how to remove it at home in the morning. Participants subsequently slept at home and returned to the lab the following evening at approximately 5:00 P.M. for the scanning session. At this time, participants returned the PSG montage to experimenters. The scanning procedure was similar to that in the first experiment, with one small exception: The incremental titration procedure to select the individual electric stimulation threshold started at $0.4 \mathrm{~mA}$ and went up in increments of two steps (again up to a maximum of $4.0 \mathrm{~mA}$ ), to encourage higher thresholds.

Fear conditioning paradigm and stimuli. Stimuli for the second study were similar to the first experiment and were comprised of two colored lights (CS) in one of two contexts, resulting in four stimulus-context pairings. During conditioning, one of the CScontext pairings (i.e., blue light in the office context) was paired with shock (US) at a partial reinforcement rate of 75\%. No US was administered for any of the other three CS-context pairings. Like the first experiment, there were 32 trials in the conditioning paradigm (eight of each CS-context pairing). However, unlike the first experiment, the trials were not blocked. To examine conditioning, the analyses presented here were restricted to two of the four CS-context pairings, the one that included the US (CS+) and the one in the same context that was never paired with the US (CS-).

Polysomnographic recording montage. Polysomnographic recording was performed using the Somte PSG mobile recording system (Compumedics). The recording montage included six EEG channels (F3, F4, C3, C4, O1, and O2) referenced to contralateral mastoids (A1, A2), as well as two EOG channels (both outer canthi, one above and one below the eye) and two channels
Table 3. Region of interest analysis for Experiment 1

\begin{tabular}{|c|c|c|c|c|c|c|}
\hline \multirow[b]{2}{*}{ Session/region/effect } & \multicolumn{3}{|c|}{ MNI coordinates } & \multirow{2}{*}{$\begin{array}{l}\text { Number } \\
\text { of voxels }\end{array}$} & \multirow[b]{2}{*}{ Zvalue } & \multirow[b]{2}{*}{$p$ value } \\
\hline & $x$ & $y$ & $Z$ & & & \\
\hline \multicolumn{7}{|l|}{ Conditioning } \\
\hline \multicolumn{7}{|l|}{ Amygdala } \\
\hline Activation only & 58 & 65 & 28 & 95 & 2.91 & 0.002 \\
\hline Activation $+S C R$ & 33 & 65 & 29 & 32 & 2.12 & 0.017 \\
\hline Activation + REM & 57 & 66 & 27 & 29 & -2.41 & 0.008 \\
\hline Activation + \%REM & 58 & 65 & 28 & 12 & -1.91 & 0.028 \\
\hline \multicolumn{7}{|l|}{ Hippocampus } \\
\hline Activation only & 61 & 47 & 27 & 433 & -3.48 & $<0.001$ \\
\hline Activation + REM & 26 & 55 & 25 & 55 & -2.39 & 0.008 \\
\hline Activation + \%REM & 26 & 55 & 25 & 15 & -2.58 & 0.005 \\
\hline \multicolumn{7}{|l|}{ vmPFC } \\
\hline Activation only & 45 & 81 & 28 & 721 & -3.59 & $<0.001$ \\
\hline Activation + REM & 40 & 81 & 28 & 42 & -2.29 & 0.011 \\
\hline Activation + \%REM & 45 & 89 & 25 & 167 & -2.98 & 0.001 \\
\hline \multicolumn{7}{|l|}{ Extinction } \\
\hline \multicolumn{7}{|l|}{ Amygdala } \\
\hline Activation only & 61 & 62 & 21 & - & 2.18 & 0.015 \\
\hline \multicolumn{7}{|l|}{ vmPFC } \\
\hline Activation only & 54 & 76 & 29 & 2 & 2.65 & 0.004 \\
\hline \multicolumn{7}{|l|}{$\operatorname{Recall}\left(\mathrm{CS}_{\mathrm{E}}+>\mathrm{CS}-\right)$} \\
\hline \multicolumn{7}{|l|}{ Hippocampus } \\
\hline Activation only & 35 & 41 & 36 & - & -2.25 & 0.012 \\
\hline \multicolumn{7}{|l|}{ vmPFC } \\
\hline Activation only & 52 & 84 & 28 & 2 & 2.65 & 0.004 \\
\hline \multicolumn{7}{|c|}{ Generalization $\left(\mathrm{CS}_{U}+>\mathrm{CS}-\right)$} \\
\hline \multicolumn{7}{|l|}{ Hippocampus } \\
\hline Activation only & 62 & 58 & 25 & 3 & -2.43 & 0.008 \\
\hline \multicolumn{7}{|l|}{ vmPFC } \\
\hline Activation only & 51 & 84 & 27 & - & 2.02 & 0.022 \\
\hline
\end{tabular}

The table shows results for the GLM analysis in Experiment 1, for each session, ROI, and contrast. Reported above are the MNI coordinates, $z$ values, and uncorrected $p$ values for the peak voxel within the cluster, as well as the size of cluster. Corrected $p$ values are noted in the text. The number of voxels is calculated based on a cluster-forming threshold of activation of $z=2.3$. In cases where peak activation did not reach this threshold, the number of voxels is not indicated.

of submental EMG (referenced to a third submental electrode). The full montage was applied in the lab by experimenters, and subjects were subsequently sent home to sleep. In the morning, participants removed the PSG montage and returned it to the lab. Sleep scoring was conducted by a licensed sleep technician (Sleep Scoring Services) using standard American Academy of Sleep Medicine criteria (Iber et al., 2007).

Data processing. Behavioral and imaging analyses were conducted in the same manner as in the first study. As in the first experiment, the conditioning contrast was defined as the first four CS + compared with all eight of the CS - trials. In accordance with the a priori hypotheses derived from the first experiment (i.e., that REM should be associated with reduced fear-related activity), only SCR and REM were entered into the GLM analysis as covariates. For the SCR analyses, one subject was excluded due to a mechanical failure during the scanning session. 

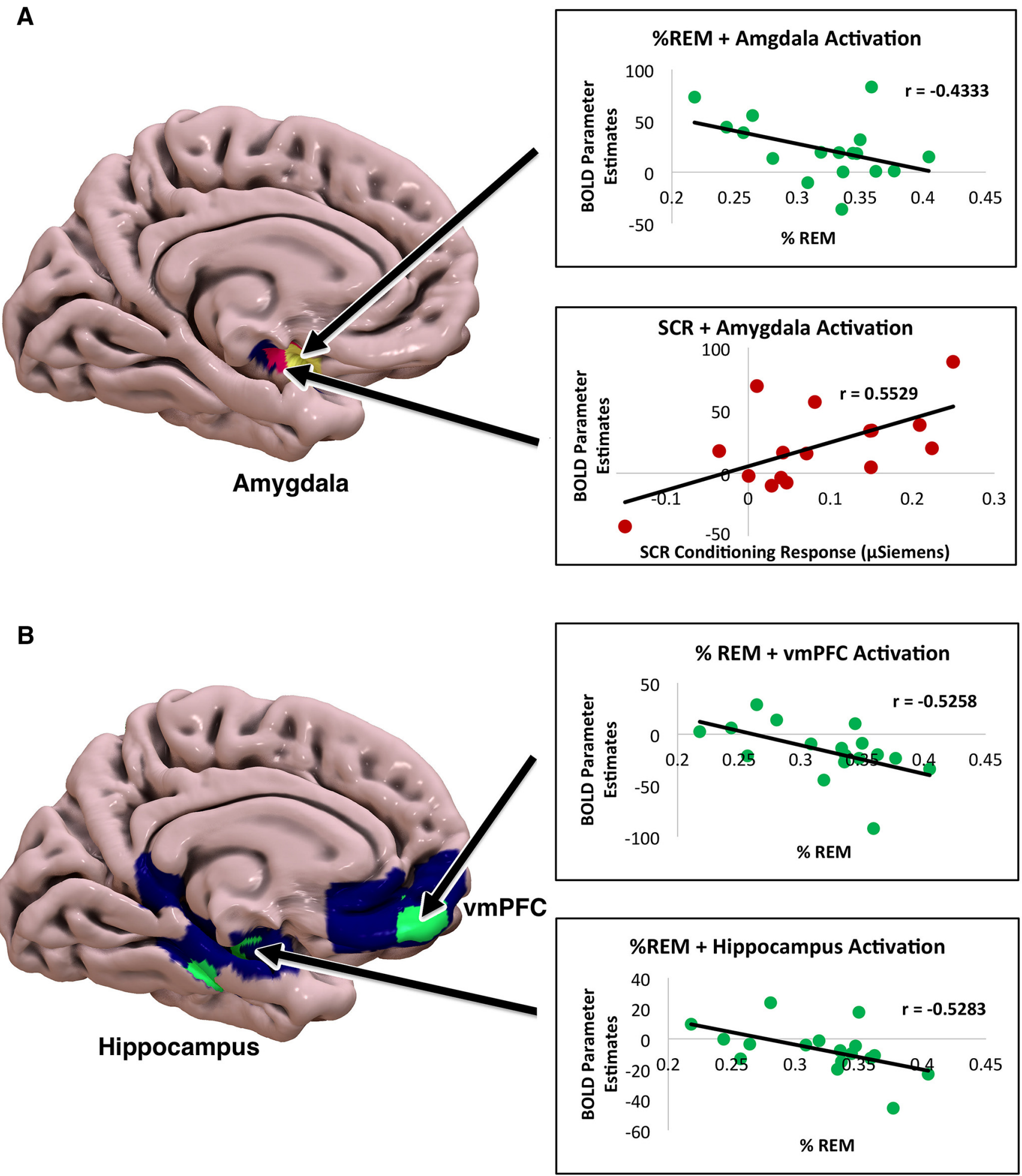

Figure 4. Results of ROl analysis for amygdala $(\boldsymbol{A})$ and the VmPFC and hippocampus $(\boldsymbol{B})$ in conditioning. Blue indicates activation only; green indicates activation that covaried with REM; red indicates activation that covaried with SCR; yellow indicates activation covarying with both REM and SCR. The scatter plots depicted in this figure (and Fig. 8) were created by obtaining the average parameter estimates for each subject (across the significant overlapping voxels) and plotting them against either the percentage REM or SCR response.

\section{Results}

Experiment 1

Skin Conductance Recordings

Average shock intensity was $1.51 \pm 0.25 \mathrm{~mA}$ ( \pm SEM; range, $0.6-$ $4.0 \mathrm{~mA}$ ). Paired $t$ tests revealed that during conditioning, the SCR values for the CS+ were significantly larger than those for the
CS $-\left(t_{(15)}=3.0168 ; p=0.0087\right.$; Fig. $\left.3 A\right)$, indicating subjects learned to discriminate between the two cues. [CS + was defined here as the average across both the $\mathrm{CS}_{\mathrm{E}}+$ and the $\mathrm{CS}_{\mathrm{U}}+$ because at this point in the experiment, the two CS+'s were not yet differentiated in the subject's view; this was verified by the lack of differential SCR between them $\left(t_{(15)}=-0.3658, p=0.7196\right)$.] In 
A

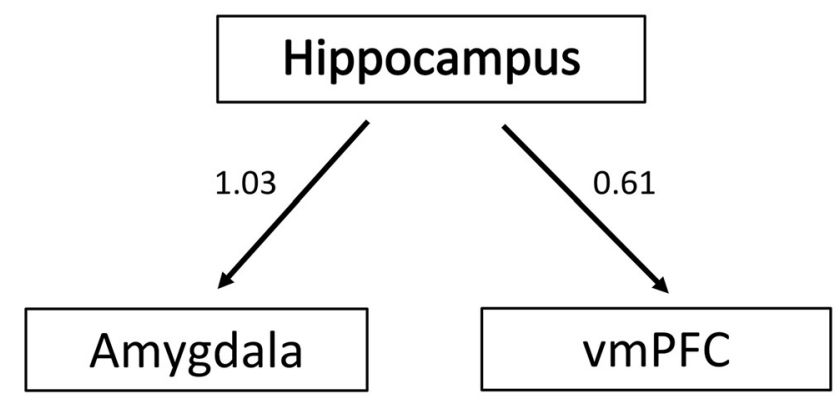

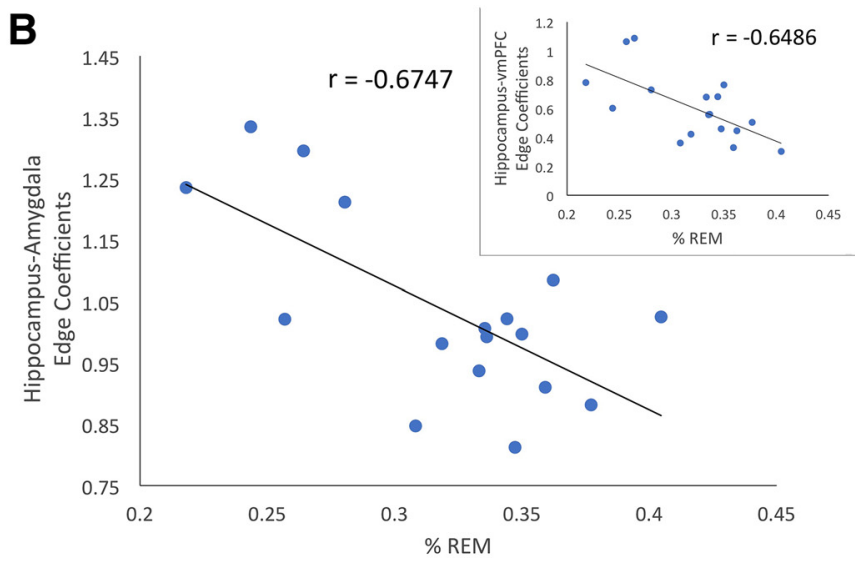

Figure 5. A, Graphical causal model of connectivity. The model suggests that the hippocampus mediates both amygdala and vmPFC activity (average strength of each connection is noted near the corresponding arrow). $\boldsymbol{B}$, Correlations across subjects between average percentage of REM out of total sleep time and hippocampus-amygdala (primary foreground) and hippocampus-vmPFC (inset) edge coefficients.

the extinction phase, the difference between the $\mathrm{CS}_{\mathrm{E}}+$ and the CS - disappeared $\left(t_{(15)}=0.4966, p=0.6267\right.$, Fig. $\left.3 B\right)$, suggesting that the $\mathrm{CS}_{\mathrm{E}}+$ was successfully extinguished.

An ANOVA for the three CS types during the recall phase showed no significant effect $\left(F_{(2,30)}=1.061, p=0.359\right.$, Fig. $\left.3 C\right)$. Nevertheless, since there was a numerical difference between the CS types, we wanted to examine how those values compared with the original conditioning effect. A $2 \times 3$ ANOVA with Session (conditioning, recall) and CS type $\left(\mathrm{CS}_{\mathrm{U}}+, \mathrm{CS}_{\mathrm{E}}+, \mathrm{CS}-\right.$; in the conditioning phase we differentiated the $\mathrm{CS}+$ trials into the "tobe" $\mathrm{CS}_{\mathrm{E}}+$ and "to-be" $\mathrm{CS}_{\mathrm{U}}+$ trials, although they were not differentiated from the subject's point of view) as within-subject factors showed that only the effect of CS-type was significant $\left(F_{(2,32)}=3.648, p=0.044\right)$; neither the effect of session nor the interaction between the two factors was significant $\left(F_{(1,16)}=\right.$ $0.655, p=0.430$ and $F_{(2,32)}=0.670, p=0.519$, respectively). This indicates that the difference acquired during conditioning was regained to some degree in the recall session (i.e., there was some fear recall), but there were no indications of generalization effects, that is, no differentiation between $\mathrm{CS}_{\mathrm{E}}+$ and $\mathrm{CS}_{\mathrm{U}}+$ with respect to the $\mathrm{CS}-$.

\section{ROI analyses}

We examined whether fear response modulated activation in three brain regions, the amygdala, the hippocampus, and the vmPFC, chosen a priori based on their established roles in fear learning (Pace-Schott et al., 2015). Activity, as well as its covariation with SCR and sleep measurements, was assessed for each contrast of interest in each session (see above, Methods). Covariance between sleep parameters and/or SCR with the activation data was considered only for voxels that overlapped with the activation-only data. Results are summarized in Table 3.

For the conditioning phase, all three a priori ROIs showed significant activation. Specifically, the amygdala showed increased activity for the $\mathrm{CS}+\left(\right.$ combined $\mathrm{CS}_{\mathrm{E}}+$ and $\left.\mathrm{CS}_{\mathrm{U}}+\right)$ compared to the CS $-(z=2.91, p=0.008$; Fig. $4 A)$, whereas the hippocampus $(z=-3.48, p<0.001)$ and the $\operatorname{vmPFC}(z=-3.58, p<0.001)$ showed the inverse pattern (i.e., more activity for the CS - than the combined CS+; Fig. 4B). The contrast in amygdala activity between the CS conditions covaried positively with the SCR contrast at a trend level $(z=2.12, p=0.066)$, and negatively with the average amount of time in $\operatorname{REM}(z=-2.41, p=0.032)$. A complementary analysis with percentage of time spent in REM as the covariate showed that the effect remained significant $(z=$
Table 4. Correlations (values and significance levels) between sleep and IMaGES edge coefficients

\begin{tabular}{|c|c|c|c|c|}
\hline \multirow[b]{2}{*}{ Sleep parameters } & \multicolumn{2}{|c|}{ Hippocampus-Amygdala } & \multicolumn{2}{|c|}{ Hippocampus-vmPFC } \\
\hline & $r$ & $p$ & $r$ & $p$ \\
\hline$S C R$ contrast $(\mu S)$ & 0.0944 & 0.7279 & -0.0447 & 0.8694 \\
\hline TST (minutes) & -0.3745 & 0.1386 & 0.4089 & 0.1466 \\
\hline N1/N2 (minutes) & 0.1176 & 0.6530 & 0.4589 & 0.0989 \\
\hline$\% N 1 / N 2$ & 0.4464 & 0.0725 & 0.2785 & 0.2791 \\
\hline SWS (minutes) & -0.0515 & 0.8444 & 0.4350 & 0.1201 \\
\hline \%SWS & 0.0425 & 0.8712 & 0.2324 & 0.3694 \\
\hline REM (minutes) & -0.7823 & 0.00021 & -0.6910 & 0.0021 \\
\hline$\%$ REM & -0.6747 & 0.0030 & -0.6486 & 0.0049 \\
\hline
\end{tabular}

Presented are uncorrected $p$ values. Significant effects after the application of Bonferroni corrections for multiple comparisons are emphasized in bold.

$-1.91, p=0.028$; Fig. $4 A$ ). These results suggested that the less REM sleep the subject had, and the higher the SCR-based fear response, the more the amygdala differentiated between threatening and nonthreatening stimuli. The average duration of REM also covaried negatively with hippocampal and vmPFC activity $(z=-2.39, p=0.032$ and $z=-2.29, p=0.011$, respectively). Furthermore, the percentage of REM also covaried negatively with both hippocampal and $\operatorname{vmPFC}(z=-2.58 p=$ $0.005 ; z=-2.98, p=0.001$; Fig. $4 B$ ), indicating that more REM was associated with smaller vmPFC and hippocampal differentiation between threatening and nonthreatening stimuli.

During the extinction phase, only the vmPFC showed significant activation, with increased activity for the $\mathrm{CS}_{\mathrm{E}}+$ compared to the $\mathrm{CS}-(z=2.65, p=0.016)$. Amygdala activity showed a similar effect at a trend level $(z=2.18, p=0.059)$. Neither SCR nor any of the sleep parameters modulated these effects.

In the recall session, fear-recall-related activation was exhibited in the vmPFC with increased activity for the $\mathrm{CS}_{\mathrm{E}}+$ compared to the CS $-(z=2.65, p=0.016)$ and decreased activity in the hippocampus for the same contrast $(z=-2.25, p=0.047)$. The generalization contrast showed the same pattern of activation: There was a trend toward increased activity in the vmPFC for the $\mathrm{CS}_{\mathrm{U}}+$ compared to the CS $-(z=2.02, p=0.085)$ and a significant decrease in hippocampal activity $(z=-2.43, p=0.032)$. As with the extinction phase, neither the SCR nor any of the sleep parameters covaried significantly with these ROI activations. Given that there were no significant correlations with REM sleep during the extinction and recall phases, and given that these 

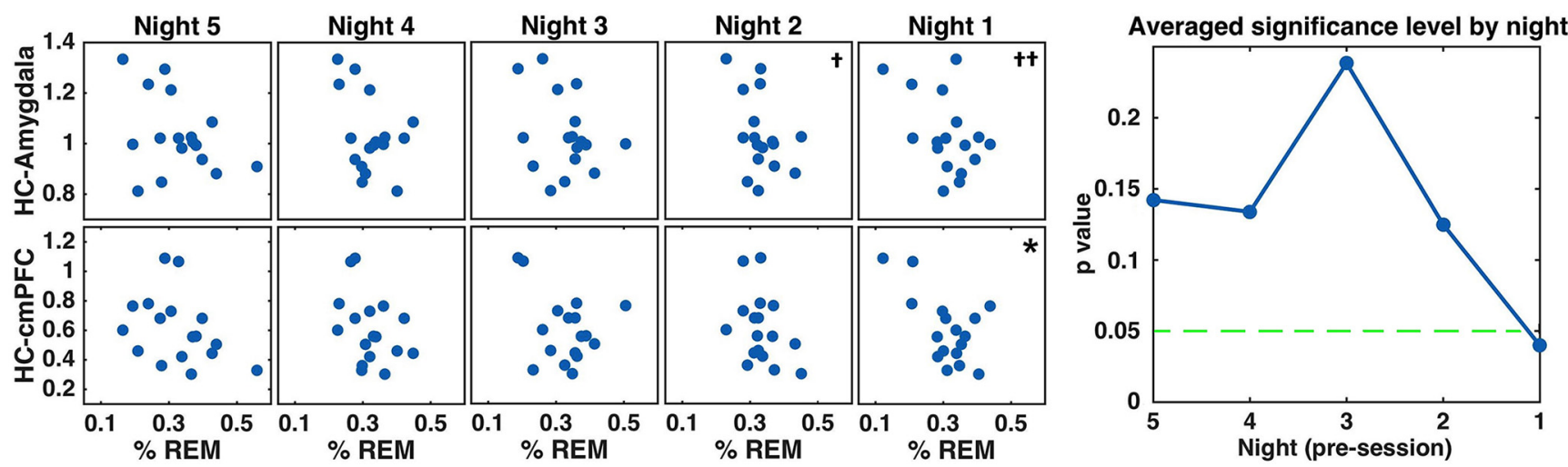

Figure 6. Daily correlations between percentage of REM sleep out of total sleep time and the edge coefficients of the hippocampus-amygdala and hippocampus-vmPFC connections. Left, Correlations for each of the five nights preceding the conditioning session (in reverse order, from the earliest night to the night just before the session). Right, The average $p$ value over the two connections as a function of night. ${ }^{\dagger} p<0.1 ;{ }^{\dagger \dagger} p<0.07 ;{ }^{*} p<0.02$.

phases also produced far less activity compared to conditioning, subsequent analyses were restricted to the conditioning phase.

Effective connectivity analysis

To detect causal relationships between the three regions of interests during fear conditioning, we ran an effective connectivity analysis using graphical causal modeling with the IMaGES and LOFS algorithms, as described in Methods. The results of this analysis are presented in Figure $5 A$. The graph reveals that the hippocampus modulated the activity of both the amygdala (edge mean $\pm \mathrm{SD}, 1.03 \pm 0.15$ ) and the vmPFC (edge mean $\pm \mathrm{SD}, 0.61 \pm 0.22$ ). To determine whether these connections were associated with sleep or SCR measures, we computed Pearson's correlations across participants between the edge coefficients of the connections and the (1) SCR conditioning contrast, (2) the baseline time spent in each of the sleep stages as well as the total sleep time, and (3) the percentage of time in these stages out of the total sleep time. Values for each of these correlations and (uncorrected) significance values are presented in Table 4 . We again took a conservative approach and applied Bonferroni corrections to each $p$ value for the eight comparisons. The analysis revealed that the average time spent in REM was negatively correlated with both the hippocampusamygdala and the hippocampus-vmPFC connections $\left(r_{(16)}=\right.$ $-0.7823, p<0.001$ and $r_{(16)}=-0.6910, p=0.0112$, respectively; Figure $5 B$ ). Additionally, the average percentage of REM was also negatively correlated with both the hippocampus-amygdala and hippocampus-vmPFC connections $\left(r_{(16)}=-0.6747, p=0.008\right.$ and $r_{(16)}=-0.6486 p=0.020$, respectively; Figure $\left.5 B\right)$. No correlations were found between the SCR and either of the connections.

Finally, one question arising from these results is whether the relationship between REM sleep and fear acquisition is a traitlevel effect, whereby individuals with ordinary high levels of REM sleep (as measured by averaging over multiple nights) also tend to have smaller conditioning effects, or, alternatively, the influence may be more temporal, with REM sleep in the night(s) just before conditioning attenuating subsequent fear acquisition. In our previous study (Lerner et al., 2016), we found that daily measures of overnight sleep were less reliable in predicting cognitive effects compared to sleep measures averaged over multiple days. To study this question, we reexamined the correlations between the edge coefficients and REM sleep in each of the last five nights before conditioning. This analysis revealed a pattern similar to that of our previous study (Fig. 6, left): No single night yielded an effect as strong as the one achieved from averaging over multiple nights. Nevertheless, while effects did not reach statistical significance for most nights, they did come closer to significance as the experimental session drew nearer (Fig. 6, right).

To conclude, consistent with previous findings in the literature (Milad et al., 2007a), our results corroborate that contextual fear learning in humans is modulated by the activity in, and connectivity between, the amygdala, hippocampus, and vmPFC. However, importantly, we also found that average levels of REM sleep prior to fear conditioning were a reliable predictor of activation in these three regions during initial fear acquisition, a finding that was previously reported only in rats (Polta et al., 2013). This effect suggests that REM sleep may not only contribute to fear processing following exposure to threat, as was shown in the past, but is also involved in modulating the brain circuitry responsible for the initial fear learning itself.

To further substantiate our conclusions from Experiment 1, we next analyzed data collected in our lab from a different but 


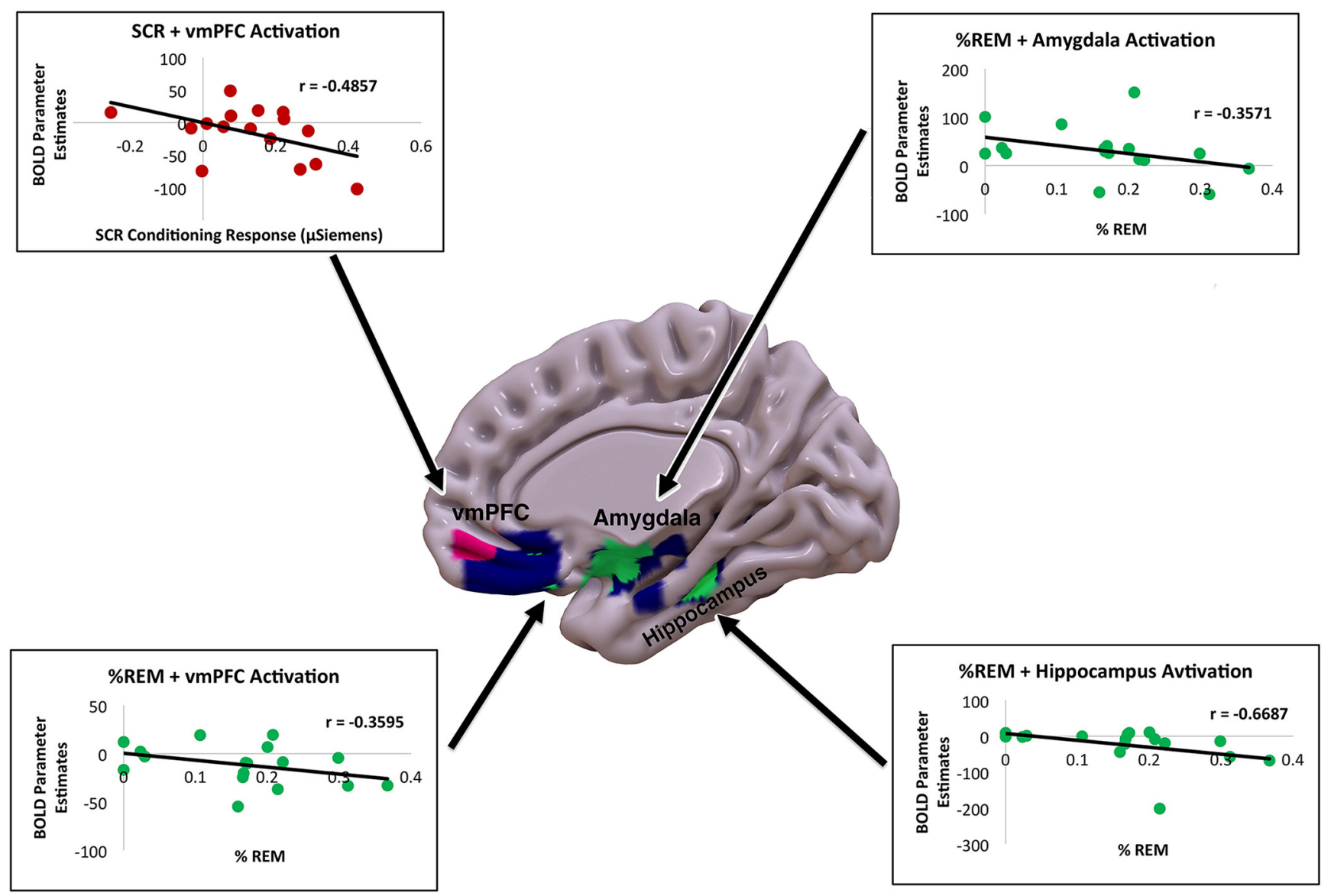

Figure 8. Results of the ROI analysis for Experiment 2. Blue indicates activation only; red indicates activation that covaried with SCR; green indicates activation that covaried with REM.

related study. In this second study, subjects slept with a full mobile polysomnography device for a single night before undergoing a fear conditioning paradigm during a functional brainimaging scan. The analyses conducted for this second experiment mirrored those of the first, using the polysomnography data in place of the averaged data from the wireless sleep-monitoring device. Based on the results from Experiment 1, we hypothesized that REM and the percentage of REM sleep would reliably predict the degree of activation in and connectivity between the amygdala, hippocampus, and vmPFC during the ensuing conditioning session, though to a smaller degree given that only a single night of sleep was measured.

\section{Experiment 2}

SCR analysis

Average shock intensity was $2.13 \mathrm{~mA} \pm 0.25 \mathrm{SEM}$ (range, $0.6-4.0$ $\mathrm{mA}$ ). Raw SCR values were higher in this experiment compared to the first (0.11 vs $0.55 \mu \mathrm{S}$ in Experiments 1 and 2, respectively), likely the result of the difference in titration procedures yielding marked differences in stimulation thresholds. To examine conditioning, a paired $t$-test revealed that the SCR values for the CS + were significantly larger than the CS $-\left(t_{(15)}=3.3581 ; p=\right.$ 0.0053 ; Fig. 7), indicating subjects learned to accurately discriminate between the threatening and the nonthreatening stimuli.

ROI analysis

Analysis of activation revealed that, similar to the first experiment, the amygdala showed increased activation for the CS+ compared to the CS $-(z=3.79, p<0.01)$, and this activity negatively covaried with the amount of time in REM sleep $(z=$
Table 5. Region of interest analysis for Experiment 2

\begin{tabular}{|c|c|c|c|c|c|c|}
\hline \multirow[b]{2}{*}{ Session/region/effect } & \multicolumn{3}{|c|}{ MNI coordinates } & \multirow{2}{*}{$\begin{array}{l}\text { Number } \\
\text { of voxels }\end{array}$} & \multirow[b]{2}{*}{$z$ value } & \multirow[b]{2}{*}{$p$ value } \\
\hline & $x$ & $y$ & $z$ & & & \\
\hline \multicolumn{7}{|l|}{ Conditioning } \\
\hline \multicolumn{7}{|l|}{ Amygdala } \\
\hline Activation only & 54 & 62 & 27 & 309 & 3.79 & $<0.001$ \\
\hline Activation + REM & 31 & 67 & 27 & 56 & -3.18 & 0.001 \\
\hline Activation + \%REM & 37 & 63 & 30 & 103 & -3.06 & 0.001 \\
\hline \multicolumn{7}{|l|}{ Hippocampus } \\
\hline Activation only & 30 & 49 & 26 & 16 & -2.75 & 0.003 \\
\hline Activation + REM & 33 & 42 & 41 & 14 & -2.88 & 0.002 \\
\hline Activation + \%REM & 29 & 49 & 26 & 5 & -2.64 & 0.010 \\
\hline \multicolumn{7}{|l|}{ vmPFC } \\
\hline Activation only & 41 & 86 & 24 & 18 & -2.77 & 0.003 \\
\hline Activation + SCR & 43 & 88 & 30 & 14 & -2.65 & 0.004 \\
\hline Activation + REM & 42 & 76 & 26 & 1 & -2.36 & 0.010 \\
\hline Activation + \%REM & 50 & 88 & 28 & 1 & -2.34 & 0.010 \\
\hline
\end{tabular}

The table shows results for the GLM analysis in Experiment 2 for ROls. Reported above are the MNI coordinates, $z$ values, and $p$ values for the peak voxel within the cluster, as well as the size of cluster. Number of voxels is calculated based on a cluster-forming threshold of activity of $z=2.3$.

$-2.86, p<0.01$; Fig. 8) as well as with the percentage of time spent in REM sleep out of total sleep time $(z=-3.06, p<0.01)$. Furthermore, the hippocampus and vmPFC again showed decreased activity for the CS + compared to the CS $-(z=-2.75$, $p<0.01$ and $z=-2.77, p<0.01$, respectively). Like the first experiment, both the average duration of REM and the percentage of REM covaried negatively with hippocampal activity $(z=$ $-2.88, p<0.01$ and $z=-2.64, p<0.01$, respectively; Fig. 8 ) and the $\operatorname{vmPFC}(z=-2.36, p<0.01$ and $z=-2.34, p<0.01$, 
A

\section{Hippocampus}

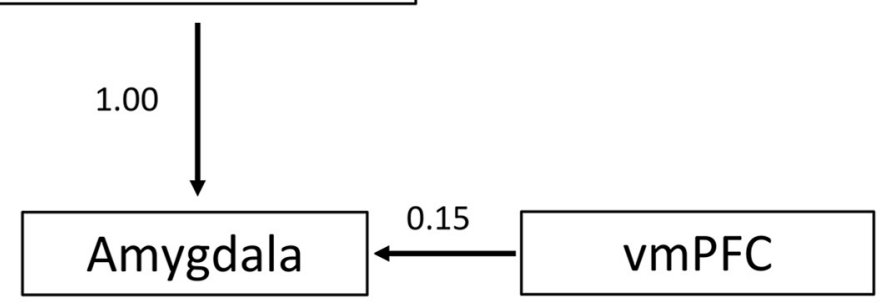

B

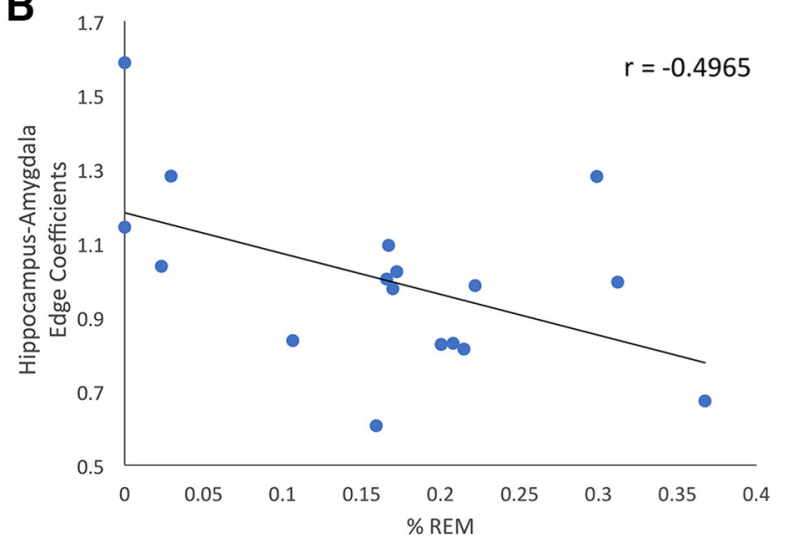

Figure 9. $A, B$, Correlations across subjects in Experiment 2 between average percent of REM out of total sleep time and hippocampus-amygdala edge coefficients.

respectively; Fig. 8). Unlike in the first experiment, there was no significant covariation with the SCR in the amygdala. However, there was significant (negative) covariation between the SCR data and vmPFC deactivation $(z=-2.65, p<0.01$; Fig. 8). Last, it is interesting to note that although the hippocampal covariation with REM was bilateral in the first experiment, it was lateralized to the right hemisphere in the second experiment. Activity in the amygdala was bilateral in both experiments. Results are summarized in Table 5.

\section{Effective connectivity analysis}

Analysis of the effective connectivity between the three brain regions using IMaGES and LOFS revealed relations that were partly consistent with the first experiment. Like before, the amygdala was modulated by the hippocampus (edge mean $\pm \mathrm{SD}, 1.00 \pm$ 0.23; Fig. 9A); however, in contrast to the first experiment, rather than the hippocampus modulating the vmPFC, the graph revealed that the vmPFC modulated the amygdala as well (edge mean $\pm \mathrm{SD}, 0.15 \pm 0.24$; Fig. $9 A$ ). Furthermore, replicating the results from the first experiment, percentage of time spent in REM was negatively correlated with the edge coefficients of the hippocampus-amygdala connection $\left(r_{(16)}=-0.4965, p<0.05\right.$; Fig. $9 B$ ). Correlation with the raw time spent in REM also showed a weak trend $\left(r_{(16)}=-0.4038, p=0.11\right)$. The vmPFC-amygdala connection, however, did not correlate with REM sleep.

\section{Discussion}

The current study sought to examine the effects of baseline levels of sleep on neurobehavioral measures of fear learning. Across Experiments 1 and 2, we found that the typical time spent in REM sleep before conditioning predicts fear-related brain activity during conditioning, such that the more REM sleep the subject had, the weaker the fear-related effect was reflected in the activity of the amygdala, hippocampus, and vmPFC, as well as the degree of modulation of the amygdala by the hippocampus. As such, our results suggest that baseline REM sleep may act as a protectant against excessive activation in fear-related neural circuits.

On the molecular level, our results are consistent with current theories of the role of REM in the reduction of norepinephrine (NE) in limbic areas and its subsequent effects on learning. A principle function of NE is the modulation of amygdala activity in response to emotionally salient stimuli. NE is secreted by the locus coeruleus (LC) throughout both wakefulness and nonREM sleep; during REM, however, the LC is silent, reducing net NE concentrations (Aston-Jones and Bloom, 1981). According to the REM recalibration hypothesis (Goldstein and Walker, 2014), this reduction "resets" baseline levels of NE, countering its accumulation during the previous waking period. These low levels of NE allow for more selective and less sensitive amygdala activity in response to emotionally salient stimuli. Furthermore, lower levels of NE activate $\alpha-1$ receptors in the vmPFC, allowing the vmPFC to send inhibitory signals to the amygdala and thus further reduce fear responding. Extrapolating from this theory, our results suggest that higher levels of baseline REM create relatively lower baseline NE levels and, in turn, reduce conditioned fear responses through a simultaneous decrease in amygdala and increase in vmPFC activity.

Though the results across the two studies were largely analogous, some differences did exist. Whereas Experiment 1 showed SCR to be positively correlated with amygdala activity, it was negatively correlated with the vmPFC in Experiment 2. Additionally, in Experiment 1, the connectivity analyses showed hippocampal modulation of both the amygdala and the vmPFC, whereas in Experiment 2 it modulated only the amygdala (the amygdala was also modulated by the vmPFC). One possible reason for these differences is the relatively small sample size in each experiment. In such cases, only the strongest effects tend to repeat, whereas weaker ones (e.g., the correlation between SCR and activity) may vary. Another option, though speculative, is that the two experiments tap slightly different processes. According to existing models, the amygdala generates a fear response when specific cues consistently predict threat, whereas the vmPFC detects safety signals that violate these predictions and inhibits amygdala activity, thereby reducing the fear response (Pape and Pare, 2010; Andrade et al., 2011; Spoormaker et al., 2011, 2012; Moustafa et al., 2013). The addition of a second, nonshocked context in Experiment 2 may have served as a partial safety signal, and therefore prompted a more safety-signal-driven modulation of neural activity. In Experiment 1, where safety signals were less conspicuous, the vmPFC may have not modulated the amygdala, and thus the amygdala activity positively correlated with SCR. In Experiment 2, where detection of safety signals was emphasized with the addition of a nonshocked context, the amygdala may have been inhibited by the vmPFC and thus the vmPFC activation correlated negatively with SCR.

Whereas both REM sleep and SCR covaried with neural activity, there was no direct correlation between REM and SCR in either experiment. One interpretation of this result is that REM sleep modulates fear-learning circuitry without modulating the actual acquisition of fear response during the experiment. Another possibility is that SCR and neural measurements capture 
different aspects of the fear learning process. An intuitive analogy for the latter interpretation can be found in the relationship between weight, height, and eating habits: while both eating habits and height are correlated with weight, the two are not necessarily related to each other. Similarly, if neural activity during conditioning reflects the strength of the formed association between the CS and US, it may be influenced by both one's individual level of stress (reflected in SCR) and by the NE-modulated sensitivity levels in the amygdala (affected by REM sleep according to the REM recalibration hypothesis; Goldstein and Walker, 2014). Thus, while stress and REM may both contribute to neural activity, they are not necessarily related to each other (for discussion of the strengths and weaknesses of SCR as a measure of fear responses, see also Figner and Murphy, 2011). Ultimately, more studies are required to distinguish between these two possible interpretations.

Two previous human studies did not find correlations between sleep parameters and subsequent conditioning. Nevertheless, key differences distinguish these studies from ours. Marshall et al. (2014) correlated conditioning with the difference in REM between an adaptation night and a subsequent night. Therefore, their null result speaks more of adaptation effects rather than baseline sleep. Also, critically, no brain activation was measured in that study. Peters et al. (2014) found no effects of partial sleep deprivation on subsequent conditioning-related brain activation. However, the authors admit that their single-night manipulation may not have been sufficient to elicit an effect (cf. Lerner et al., 2016), and, moreover, functional connectivity between relevant areas was not examined at all.

Our results suggest that while it is possible to identify associations between REM and subsequent markers of fear acquisition based on a single night of measuring, effects are substantially stronger when assessing REM over multiple nights. This might suggest a trait-level relation whereby the regular amount of REM sleep characterizing the individual sets the tone to any future level of conditioning. On the other hand, when single nights were compared, there seem to have been a weak trend toward higher correlations the closer the night was to the fear learning session (Fig. 6). It is thus possible that both trait-level and state-level effects contribute to the results, a conclusion that would be consistent with previous findings from our lab (Lerner et al., 2016). Trait versus state effects may also play a role when considering that, unlike some prior studies, we did not find any relationship between sleep and measures of fear extinction (Day 1) or recall (Day 2). With few exceptions, nearly all previous studies reporting such effects were based on sleep measures taken after conditioning. It is therefore possible that these results are predominantly conditioning driven (i.e., state-like) and would not be present in looking at baseline, preconditioning sleep. Moreover, the literature about the effects of REM on the various components of fear learning is equivocal; some studies show that REM sleep increases recall of previously encoded fear (Menz et al., 2013), others shows that REM decreases fear recall (Fu et al., 2007), and yet others suggest that REM increases the rate of extinction learning and its later preservation (Silvestri, 2005; Spoormaker et al., 2012). Failing to take under consideration both trait- and state-level effects of sleep, and their possible interaction, may have contributed to these contradicting findings if, for example, baseline levels of REM sleep affect fear acquisition, which, in turn, affects subsequent sleep, which affects subsequent extinction, and so on.

The results of our first experiment are based on sleep staging data from an automated sleep-monitoring system. This device, though repeatedly validated against PSG (Shambroom et al.,
2012; Griessenberger et al., 2013), has been reported to occasionally inflate (systematically) the number of REM epochs toward the beginning of the night. This may have been reflected in our results, showing the average time in REM sleep reached $32 \%$ of total sleep time across subjects, compared to the roughly $25 \%$ typically reported for that age group (Gillin et al., 1981). On the opposite end of the spectrum, the average percentage of REM out of total sleep time in the second experiment was lower than the norm $(17 \%)$. This low percentage is likely due to first night effects (Le Bon et al., 2001), a phenomenon characterized by alterations in sleep due to a new and/or uncomfortable environment (e.g., wearing the PSG montage). Nevertheless, despite the marked difference in average REM percentage, the effects of REM on fear learning were similar across experiments.

Ultimately, our results may suggest that baseline REM sleep could serve as a noninvasive biomarker for resilience, or susceptibility, to trauma. Current studies of sleep in individuals with PTSD have shown REM abnormalities such as low levels of REM and REM fragmentation (Mellman et al., 1997). Our results raise the possibility that these REM deficiencies actually predate the trauma and are not a consequence of the disorder. In line with this prediction, several studies have suggested that self-reported sleep abnormalities exist before trauma in individuals who later go on to develop PTSD (Mellman et al., 1995; Wright et al., 2011; Gehrman et al., 2013). As such, collecting accurate baseline measures of sleep architecture may be useful in determining suitability for occupations that have higher rates of trauma exposure.

\section{References}

Ancoli-Israel S, Cole R, Alessi C, Chambers M, Moorcroft W, Pollak CP (2003) The role of actigraphy in the study of sleep and circadian rhythms. Sleep 26:342-392. CrossRef Medline

Andrade KC, Spoormaker VI, Dresler M, Wehrle R, Holsboer F, Sämann PG, Czisch M (2011) Sleep spindles and hippocampal functional connectivity in human NREM sleep. J Neurosci 31:10331-10339. CrossRef Medline

Aston-Jones G, Bloom FE (1981) Activity of norepinephrine-containing locus coeruleus neurons in behaving rats anticipates fluctuations in the sleep-waking cycle. J Neurosci 1:876-886. Medline

Cole RJ, Kripke DF, Gruen W, Mullaney DJ, Gillin JC (1992) Automatic sleep/wake identification from wrist activity. Sleep 15:461-469. CrossRef Medline

Dégenètais E, Thierry AM, Glowinski J, Gioanni Y (2003) Synaptic influence of hippocampus on pyramidal cells of the rat prefrontal cortex: an in vivo intracellular recording study. Cereb Cortex 13:782-792. CrossRef Medline

de Souza L, Benedito-Silva AA, Pires ML, Poyares D, Tufik S, Calil HM (2003) Further validation of actigraphy for sleep studies. Sleep 26:81-85. CrossRef Medline

Figner B, Murphy, R. O (2011) Using skin conductance in judgment and decision making research. In: A handbook of process tracing methods for decision research: a critical review and user's guide, pp 163-184. New York: Psychology.

Fullana M, Harrison BJ, Soriano-Mas C, Vervliet B, Cardoner N, Àvila-Parcet A, Radua J (2016) Neural signatures of human fear conditioning: an updated and extended meta-analysis of fMRI studies. Mol Psychiatry 21: 500-508. CrossRef Medline

Fu J, Li P, Ouyang X, Gu C, Song Z, Gao J, Han L, Feng S, Tian S, Hu B (2007) Rapid eye movement sleep deprivation selectively impairs recall of fear extinction in hippocampus-independent tasks in rats. Neuroscience 144: 1186-1192. CrossRef Medline

Gehrman P, Seelig AD, Jacobson IG, Boyko EJ, Hooper TI, Gackstetter GD, Ulmer CS, Smith TC (2013) Predeployment sleep duration and insomnia symptoms as risk factors for new-onset mental health disorders following military deployment. Sleep 36:1009-1018. CrossRef Medline

Germain A, Buysse DJ, Nofzinger E (2008) Sleep-specific mechanisms underlying posttraumatic stress disorder: integrative review and neurobiological hypotheses. Sleep Med Rev 12:185-195. CrossRef Medline

Gillin JC, Duncan WC, Murphy DL, Post RM, Wehr TA, Goodwin FK, Wyatt 
RJ, Bunney WE Jr (1981) Age-related changes in sleep in depressed and normal subjects. Psychiatry Res 4:73-78. CrossRef Medline

Goldstein AN, Walker MP (2014) The role of sleep in emotional brain function. Annu Rev Clin Psychol 10:679-708. CrossRef Medline

Griessenberger H, Heib DP, Kunz AB, Hoedlmoser K, Schabus M (2013) Assessment of a wireless headband for automatic sleep scoring. Sleep Breathing 17:747-752. CrossRef Medline

Iber C, Ancoli-Israel S, Chesson A, Quan S (2007) The AASM manual for the scoring of sleep and associated events: rules, terminology, and technical specifications. Westchester, IL: American Academy of Sleep Medicine.

Jenkinson M, Smith S (2001) A global optimisation method for robust affine registration of brain images. Med Image Anal 5:143-156. CrossRef Medline

Jenkinson M, Bannister P, Brady M, Smith S (2002) Improved optimization for the robust and accurate linear registration and motion correction of brain images. Neuroimage 17:825-841. CrossRef Medline

Le Bon O, Staner L, Hoffmann G, Dramaix M, San Sebastian I, Murphy JR, Kentos M, Pelc I, Linkowski P (2001) The first-night effect may last more than one night. J Psychiatric Res 35:165-172. CrossRef

Lerner I, Lupkin SM, Corter JE, Peters SE, Cannella LA, Gluck MA (2016) The influence of sleep on emotional and cognitive processing is primarily trait-(but not state-)dependent. Neurobiol Learn Memory 134:275-286. CrossRef

Marshall AJ, Acheson DT, Risbrough VB, Straus LD, Drummond SP (2014) Fear conditioning, safety learning, and sleep in humans. J Neurosci 34: 11754-11760. CrossRef Medline

Mellman TA, Kumar A, Kulick-Bell R, Kumar M, Nolan B (1995) Nocturnal/daytime urine noradrenergic measures and sleep in combat-related PTSD. Biol Psychiatry 38:174-179. CrossRef Medline

Mellman TA, Nolan B, Hebding J, Kulick-Bell R, Dominguez R (1997) A polysomnographic comparison of veterans with combat-related PTSD, depressed men, and non-ill controls. Sleep 20:46-51. CrossRef Medline

Menz MM, Rihm JS, Salari N, Born J, Kalisch R, Pape HC, Marshall L, Büchel C (2013) The role of sleep and sleep deprivation in consolidating fear memories. Neuroimage 75:87-96. CrossRef Medline

Milad MR, Wright CI, Orr SP, Pitman RK, Quirk GJ, Rauch SL (2007a) Recall of fear extinction in humans activates the ventromedial prefrontal cortex and hippocampus in concert. Biol Psychiatry 62:446-454. CrossRef Medline

Milad MR, Quirk GJ, Pitman RK, Orr SP, Fischl B, Rauch SL (2007b) A role for the human dorsal anterior cingulate cortex in fear expression. Biol Psychiatry 62:1191-1194. CrossRef Medline

Moustafa AA, Gilbertson MW, Orr SP, Herzallah MM, Servatius RJ, Myers CE (2013) A model of amygdala-hippocampal-prefrontal interaction in fear conditioning and extinction in animals. Brain Cogn 81:29-43. CrossRef Medline

Mumford J, Ramsey J (2014) Bayesian networks for fMRI: a primer. NeuroImage 86:573-582. CrossRef Medline

Pace-Schott EF, Milad MR, Orr SP, Rauch SL, Stickgold R, Pitman RK (2009)
Sleep promotes generalization of extinction of conditioned fear. Sleep 32:19-26. Medline

Pace-Schott EF, Germain A, Milad MR (2015) Effects of sleep on memory for conditioned fear and fear extinction. Psychol Bull 141:835-857. Medline

Pape HC., Pare D (2010) Plastic synaptic networks of the amygdala for the acquisition, expression, and extinction of conditioned fear. Physiol Rev 90:419-463. CrossRef Medline

Pawlyk AC, Morrison AR, Ross RJ, Brennan FX (2008) Stress-induced changes in sleep in rodents: models and mechanisms. Neurosci Biobehav Rev 32:99-117. CrossRef Medline

Peters AC, Blechert J, Sämann PG, Eidner I, Czisch M, Spoormaker VI (2014) One night of partial sleep deprivation affects habituation of hypothalamus and skin conductance responses. J Neurophysiol 112:12671276. CrossRef Medline

Polta SA, Fenzl T, Jakubcakova V, Kimura M, Yassouridis A, Wotjak CT (2013) Prognostic and symptomatic aspects of rapid eye movement sleep in a mouse model of posttraumatic stress disorder. Front Behav Neurosci 7:60. Medline

Ramsey JD, Hanson SJ, Hanson C, Halchenko YO, Poldrack RA, Glymour C (2010) Six problems for causal inference from fMRI. NeuroImage 49: 1545-1558. Medline

Ramsey JD, Spirtes P, Glymour C (2011) On meta-analyses of imaging data and the mixture of records. NeuroImage 57:323-330. CrossRef Medline

Ramsey JD, Sanchez-Romero R, Glymour C (2014) Non-Gaussian methods and high-pass filters in the estimation of effective connections. NeuroImage, 84:986-1006. CrossRef Medline

Shambroom JR, Fábregas SE, Johnstone J (2012) Validation of an automated wireless system to monitor sleep in healthy adults. J Sleep Res 21:221-230. CrossRef Medline

Silvestri AJ (2005) REM sleep deprivation affects extinction of cued but not contextual fear conditioning. Physiol Behav 84:343-349. CrossRef Medline

Spoormaker VI, Andrade KC, Schröter MS, Sturm A, Goya-Maldonado R, Sämann PG, Czisch M (2011) The neural correlates of negative prediction error signaling in human fear conditioning. Neuroimage 54:22502256. CrossRef Medline

Spoormaker VI, Schröter MS, Andrade KC, Dresler M, Kiem SA, GoyaMaldonado R, Wetter TC, Holsboer F, Sämann PG, Czisch M (2012) Effects of rapid eye movement sleep deprivation on fear extinction recall and prediction error signaling. Hum Brain Mapp 33:2362-2376. CrossRef Medline

Walker MP, van der Helm E (2009) Overnight therapy? The role of sleep in emotional brain processing. Psychol Bull 135:731-748. CrossRef Medline

Wright KM, Britt TW, Bliese PD, Adler AB, Picchioni D, Moore D (2011) Insomnia as predictor versus outcome of PTSD and depression among Iraq combat veterans. J Clin Psychol 67:1240-1258. CrossRef Medline

Yoo SS, Hu PT, Gujar N, Jolesz FA, Walker MP (2007) A deficit in the ability to form new human memories without sleep. Nat Neurosci 10:385-392. CrossRef Medline 